\title{
IGF-IR promotes clonal cell proliferation in myelodysplastic syndromes via inhibition of the MAPK pathway
}

\author{
QI HE*, QINGQING ZHENG*, FENG XU, WENHUI SHI, JUAN GUO, \\ ZHENG ZHANG, SIDA ZHAO, XIAO LI and CHUNKANG CHANG
}

\begin{abstract}
Department of Hematology, Shanghai Jiao Tong University Affiliated Sixth People's Hospital, Shanghai 200233, P.R. China
\end{abstract}
Received September 11, 2019; Accepted May 19, 2020

DOI: 10.3892/or.2020.7652

\begin{abstract}
Type 1 insulin-like growth factor receptor (IGF-IR) signaling is considered to serve a key role in the development of cancer. However, the effects of IGF-IR on the malignant characteristics of myelodysplastic syndrome (MDS) clonal cells remains to be determined. In the present study it was demonstrated that knockdown of IGF-IR reduced the proliferation and increased the apoptosis of MDS/leukemia cells. Integrated analysis of gene expression profiles using bioinformatics identified the MAPK signaling pathway as a critical downstream factor of IGF-IR, and this was confirmed in vitro using western blotting which revealed that IGF-IR knockdown significantly increased the expression of activated MAPK. Furthermore, IGF-IR signaling was inhibited to investigate the potential of IGF-IR as a therapeutic target of MDS. The results revealed that the IGF-IR inhibitor picropodophyllin (PPP) inhibited cell proliferation, promoted cell apoptosis and arrested the cell cycle at the G2/M phase in MDS/leukemia cells. Similar to the effects of IGF-IR knockdown, PPP treatment also increased MAPK signaling in vitro. In conclusion, IGF-IR may serve as a potential therapeutic target of MDS.
\end{abstract}

\section{Introduction}

Myelodysplastic syndromes (MDS) are malignant clonal proliferative disorders of hematopoietic stem cells, which are characterized by uni- or multi-lineage cytopenias, dysplasia of bone marrow hematopoietic cells, and eventual progression to leukemia in approximately one-third of patients (1). Residual normal hematopoietic cells and malignant clonal hematopoietic cells often co-exist and compete with each

Correspondence to: Dr Chunkang Chang, Department of Hematology, Shanghai Jiao Tong University Affiliated Sixth People's Hospital, 600 Yishan Road, Shanghai 200233, P.R. China

E-mail: changchunkang@sjtu.edu.cn

${ }^{*}$ Contributed equally

Key words: myelodysplastic syndrome, IGF-IR, clonal cell, proliferation, MAPK other for a considerable period of time in the bone marrow of patients with MDS. When the malignant proliferation of bone marrow clonal cells becomes dominant, the disease progresses to acute myelocytic leukemia (AML) $(2,3)$. Patients with MDS with a bone marrow blast percentage $>5 \%$ present an increased risk of progressing to AML (1). At present, studies on the pathogenesis of malignant clonal proliferation in MDS are primarily focused on the involvement of gene mutations, downregulation of tumor suppressor genes, epigenetic abnormalities (including hypermethylation of genes and histone modification), abnormal regulations of multiple signaling pathways associated with proliferation, and abnormalities in bone marrow cell apoptosis (4-8). However, bone marrow clonal cells in MDS are also highly heterogeneous in terms of their morphology and differentiation stages, which renders studies on the mechanisms underlying malignant clonal proliferation in MDS difficult and hampers progress in the development of therapeutics.

Type 1 insulin-like growth factor receptor (IGF-IR) belongs to the tyrosine receptor family of proteins (9). IGF-IR serves an important role in regulating cell growth, proliferation, transformation, differentiation and apoptosis $(9,10)$. It has been demonstrated that IGF-IR expression is upregulated in bone marrow cells of patients with multiple myeloma, AML, chronic myeloid leukemia, acute lymphocytic leukemia as well as other hematological malignancies, or other associated tumor cell lines (11-15). Studies have also demonstrated that IGF-IR serves an important role in regulating the biological activity of cancer stem cells (16-18). In our previous studies, it was demonstrated that overexpression of IGF-IR was negatively correlated with apoptosis of bone marrow mononuclear cells (BMNCs) in patients with MDS and IGF-IR was primarily expressed on the surface of MDS clonal cells $(19,20)$. Since IGF-IR is a membrane receptor, our laboratory was able to effectively purify MDS clonal cells by labeling IGF-IR using flow cytometry. In addition, our data further revealed that the proliferation of clonal cells was significantly inhibited by the IGF-IR inhibitor picropodophyllin (PPP) (21). Our previous results indicated that overexpression of IGF-IR was associated with proliferation of clonal cells. The aim of the present study was to further investigate the underlying mechanisms governing IGF-IR-mediated clonal cell proliferation, and explore the potential of IGF-IR as a therapeutic target of MDS. 


\section{Materials and methods}

Antibodies and reagents. The following antibodies were used for western blotting: p38 MAPK (product no. 9212), phosphorylated (p-)p38 MAPK (product no. 4511), p44/42 MAPK (product no. 9102), p-p44/42 MAPK (product no. 5726), GSK (product no. 5676), p-GSK (product no. 8566), Akt (product no. 9272), p-Akt (product no. 4060) and $\beta$-actin (product no. 4970) were purchased from Cell Signaling Technology, Inc.. PPP was purchased from Santa Cruz Biotechnology, Inc.. PPP was dissolved in DMSO to a concentration of $0.5 \mathrm{mM}$. In a series of experiments, $\mathrm{CD} 34^{+}$cells were incubated with $1 \mu \mathrm{M}$ PPP in the maintenance medium (StemSpan ${ }^{\mathrm{TM}}$ SFEM 09650; StemCell Technologies).

Patients and isolation of $\mathrm{CD} 34^{+}$cells. MDS was diagnosed in accordance with the minimum diagnostic criteria (22). The classification and prognostic risk scoring of MDS were performed according to the World Health Organization (WHO) classification system, the French-American-British classification (FAB) and the International Prognostic Scoring System (IPSS) (23-25). Chromosomal abnormalities of patients were described according to International System for Human Cytogenetics Nomenclature (ISCN 2005) (26). From August 2014 to March 2015, 8 MDS patients (5 males and 3 females) were included, and all samples were obtained from patients at the time of the initial diagnosis. Detailed clinicopathological characteristics of patients recruited for the present study are presented in Table I. According to the Declaration of Helsinki, all subjects signed informed consent, and the present study was approved by the Ethics Committee of the Sixth Hospital Affiliated with Shanghai Jiao Tong University. CD34+ cells were isolated using magnetic-activated cell sorting (MACS) from BMNCs according to the manufacturer's protocol (Miltenyi Biotec). The yield and purity of the positive CD34 cells were evaluated using flow cytometry (FACS Calibur; BD Biosciences). Typically, approximately $1-5 \times 10^{6} \mathrm{CD} 34^{+}$cells were obtained from patients with MDS and used for subsequent biological experiments apart from western blotting.

Cell lines and culture. SKM-1 cells were kindly gifted from Professor Nakagawa (27). K562 cells were obtained from the American Type Culture Collection. Cell lines were maintained in complete medium (RPMI-1640 supplemented with $10 \%$ FBS, $1 \%$ glutamine, and $1 \%$ sodium pyruvate were purchased from Thermo Fischer Scientific, Inc.).

Lentivirus-mediated cell transfection. Three IGF-IR-short hairpin (sh)RNAs were inserted into the LV1 vector purchased from Shanghai Genechem Co., Ltd. (www.genechem.com. $\mathrm{cn})$. The construction of the IGF-IR-knockdown vector was confirmed using restriction digest analysis and DNA sequencing. Lentiviral packaging was performed using a four-plasmid system (pGLV1/U6/GFP Vector, pRsv-REV, pMDlg-pRRE and pMD2G). After titre determination

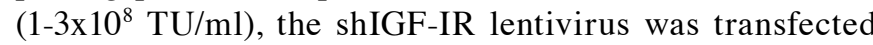
into SKM-1 cells. Briefly, $5 \times 10^{5}$ cells/well in a 6 -well plate were incubated with the virus and polybrene $(10 \mu \mathrm{g} / \mathrm{ml})$ in a $1-\mathrm{ml}$ volume. The stably expressing cells were propagated in complete RPMI-1640 medium at $37^{\circ} \mathrm{C}$ for $3-5$ days prior to subsequent experiments. There was no noticeable loss of GFP expression in the established cultures observed throughout the experiments based on fluorescence microscopy or flow cytometric analysis. Silencing efficiency of the IGF-IR vector was evaluated using reverse transcription-quantitative (RT-q) PCR. Cells with a decrease $>70 \%$ in IGF-IR mRNA expression post-transfection were used in subsequent experiments (Fig. S1).

$R N A$ extraction and $R T-q P C R$. Total RNA was extracted from $1 \times 10^{5}$ cells from either SKM-1 or K562 cells using an RNeasy system (Qiagen, Inc.) according to the manufacturer's instructions, and the RNA was reverse transcribed into cDNA. cDNA was synthesized using PrimeScript RT reagent kit (Takara Bio, Inc.). PCR amplification of IGF-IR, p21 and MYC mRNA was performed on an ABI Prism 7500 System (Applied Biosystems; Thermo Fisher Scientific, Inc.) with SYBR Green Master mix (Takara Bio, Inc.). PCR was carried out under the following cycling conditions: Initial denaturation at $9^{\circ} \mathrm{C}$ for $60 \mathrm{sec}$, followed by 40 cycles of denaturation at $95^{\circ} \mathrm{C}$ for $20 \mathrm{sec}$, annealing at $60^{\circ} \mathrm{C}$ for $30 \mathrm{sec}$ and extension at $72^{\circ} \mathrm{C}$ for $30 \mathrm{sec}$. Relative expression of IGF-IR, p21, MYC and GAPDH genes was calculated using the $2^{-\Delta \Delta \mathrm{Cq}}$ method (28). The primer sequences are presented in Table S1.

Proliferation analyses. For the colony formation assays, cells were plated in 6-well plates with methylcellulose medium containing SCF, GM-CSF, IL-3 and erythropoietin (StemCell Technologies, Inc.) at $2 \times 10^{3}$ cells/well with two wells per condition. After 14 days of incubation in a humidified incubator at $37^{\circ} \mathrm{C}$, the colonies containing $\geq 30$ cells were counted. For the cell proliferation assay, SKM-1 and K562 cells were seeded in 96-well plates at a density of $1 \times 10^{3}$ cells/well in triplicate. Cell Counting Kit-8 (CCK-8; $10 \mu \mathrm{l}$; Dojindo Molecular Technologies, Inc.) was added to each well after 24, 48, 72 or $96 \mathrm{~h}$. The absorbance value was read at $450 \mathrm{~nm}$ using an enzyme-labeled instrument. The inhibition rate of cell proliferation was calculated as follows: Percent of inhibition rate $=\left[1-\left(\mathrm{OD}^{\text {knockdown well }}-\mathrm{OD}^{\text {blank well }}\right) /\left(\mathrm{OD}^{\text {control well }}-\mathrm{OD}^{\text {blank well }}\right)\right]$ $\mathrm{x} 100 \%$. For the Trypan blue staining assay, $4 \times 10^{5} \mathrm{CD}^{2} 4^{+}$cells purified from patients with MDS or cell lines were treated with $1 \mu \mathrm{M}$ PPP for $24 \mathrm{~h}$, and an equivalent volume of DMSO was used as a negative control. The cells were stained using $0.4 \%$ Trypan Blue (Thermo Fisher Scientific, Inc.) for $3 \mathrm{~min}$ at room temperature. The unstained (viable) and stained (non-viable) cells were counted separately in the hemacytometer and the survival of cells was calculated.

Apoptosis detection. A total of $1 \times 10^{5}$ SKM- 1 or K 562 cells were stained with anti-Annexin V-APC (Lianke Biotech Co., Ltd.) for $15 \mathrm{~min}$ at room temperature, and subsequently analyzed using flow cytometry (FACSCalibur; BD Biosciences). Additionally, a total of $1 \times 10^{5}$ cells $\mathrm{CD} 34^{+}$from patients with MDS or cell lines were treated with $1 \mu \mathrm{M}$ PPP for $24 \mathrm{~h}$. Apoptosis was evaluated using flow cytometry (FACSCalibur; BD Biosciences) after staining cells with anti-Annexin V-FITC and PI (BD Pharmingen; BD Biosciences). The sum of the upper right and lower right quadrants was used for calculating total apoptosis rates and subjected to statistical analysis (BD CellQuest software 6.0; BD Biosciences). 
Table I. Clinical characteristics of MDS patients.

\begin{tabular}{lcccl}
\hline No. & Sex/age & WHO/FAB & IPSS & \multicolumn{1}{c}{ Karyotype by G-banding } \\
\hline 1 & $\mathrm{M} / 62$ & RAEB2 & 2.0 & $46, \mathrm{XY}, \operatorname{del}(5)(\mathrm{q} 13 \mathrm{q} 31)[18] / 46, \mathrm{XY}[2]$ \\
2 & $\mathrm{M} / 47$ & RAEB1 & 1.0 & $46, \mathrm{XY}[15]$ \\
3 & $\mathrm{M} / 73$ & RAEB1 & 1.5 & $46, \mathrm{XY}, \operatorname{del}(5)(\mathrm{q} 15 \mathrm{q} 31), \operatorname{inv}(9)(\mathrm{p} 12 \mathrm{q} 12)[10]$ \\
4 & $\mathrm{~F} / 55$ & $\mathrm{RA}$ & 0.5 & $47, \mathrm{XX},+8[15]$ \\
5 & $\mathrm{M} / 17$ & RCMD & 1.0 & $47, \mathrm{XY},+8[25]$ \\
6 & $\mathrm{M} / 77$ & RAEB1 & 1.0 & $46, \mathrm{XY}[14]$ \\
7 & $\mathrm{~F} / 34$ & RAEBt & 2.5 & $47, \mathrm{XX},+8[12]$ \\
8 & $\mathrm{~F} / 62$ & RAEB2 & 3.0 & $48, \mathrm{X}, \mathrm{X}, \operatorname{der}(7) \mathrm{t}(7 ; 11)(\mathrm{q} 11 \mathrm{q} 11),+3 \operatorname{mar}, \operatorname{inc}[2] / 46, \mathrm{XX}[8]$
\end{tabular}

MDS, myelodysplastic syndrome; WHO, World Health Organization; FAB, French-American-British; IPSS, International Prognostic Scoring System.
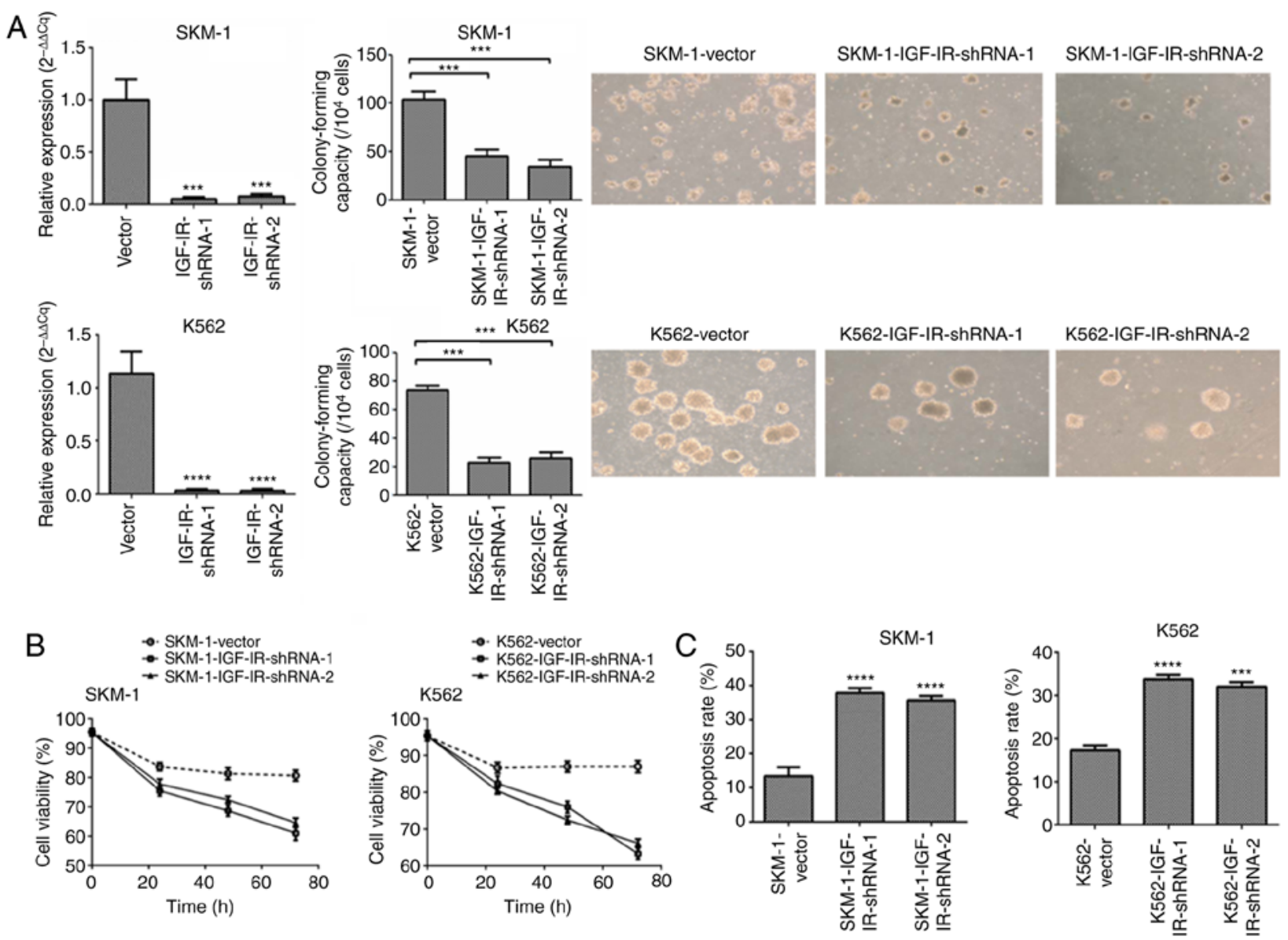

Figure 1. IGF-IR knockdown inhibits the proliferation and increases apoptosis of MDS/leukemia cell lines. (A) Transfection of IGF-IR-shRNA lentivirus resulted in a decrease in IGF-IR expression both in the SKM-1 and K562 cells. Colony formation assays revealed that SKM-1 and K562 cells with IGF-IR knockdown significantly reduced colony formation compared with the control cells. (B) Cell Counting Kit-8 assays revealed that IGF-IR knockdown inhibited cell growth compared with the control cells. (C) IGF-IR knockdown increased cell apoptosis in SKM-1 and K562 cell lines. ${ }^{* * * *} \mathrm{P}<0.001,{ }^{* * * * *} \mathrm{P}<0.0001$ (ANOVA). shRNA, short hairpin RNA; MDS, myelodysplastic syndrome; IGF-IR, type 1 insulin-like growth factor receptor.

Cell cycle analysis. A total of $5 \times 10^{5}$ cells were washed with cold PBS, re-suspended in $1 \mathrm{ml}$ of DNA staining reagent $(50 \mu \mathrm{g} / \mathrm{ml} \mathrm{PI}$ ) and $10 \mu \mathrm{l}$ RNase A was added (Lianke Biotech Co., Ltd.). Samples were incubated in the dark for $30 \mathrm{~min}$, and then analyzed using flow cytometry (FACSCalibur; BD Biosciences). The percentage of cells in the G0/G1, S and
G2/M phases were calculated using BD CellQuest software 6.0 (BD Biosciences).

Gene expression microarray (GEM). A Genechip Primeview Human Gene Expression Array (cat. no. 901837; Affymetrix; Thermo Fisher Scientific, Inc.) was used for GEM analysis. 
A

Dif gene Sig pathway (-LgP)

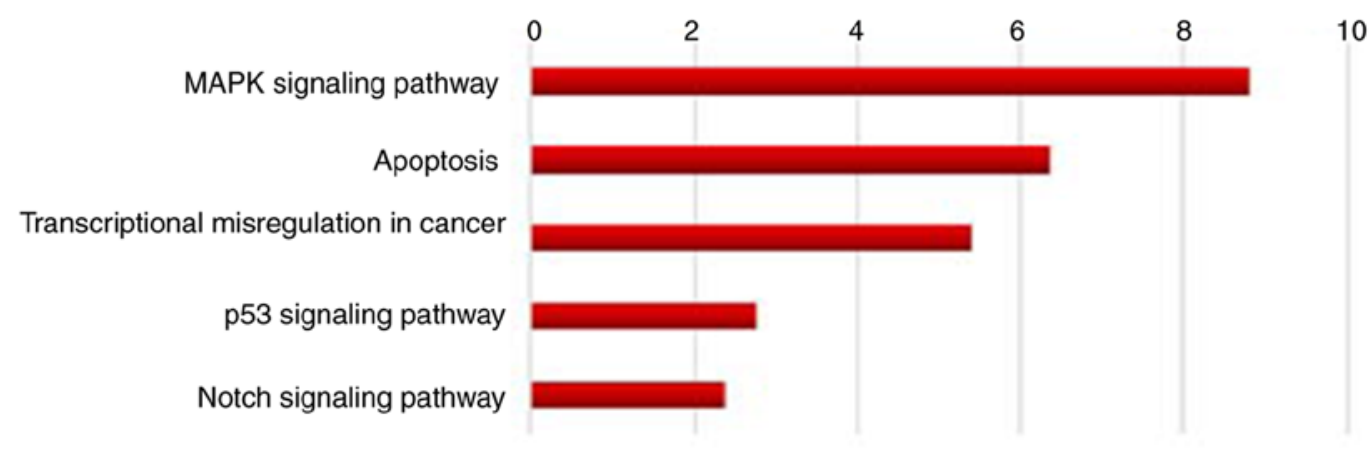

Dif gene Sig pathway (-LgP)

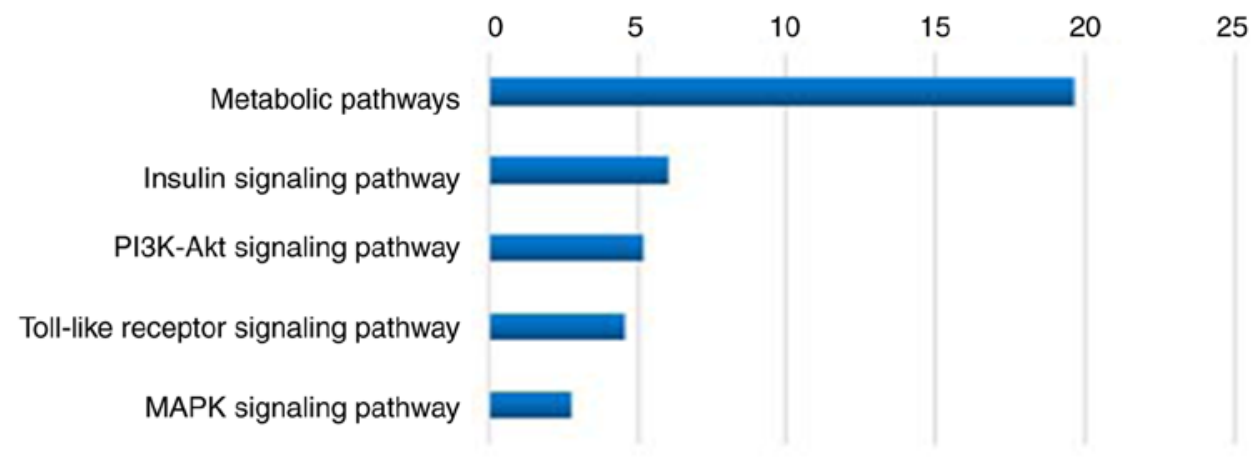

B

Dif gene Sig GO (-LgP)

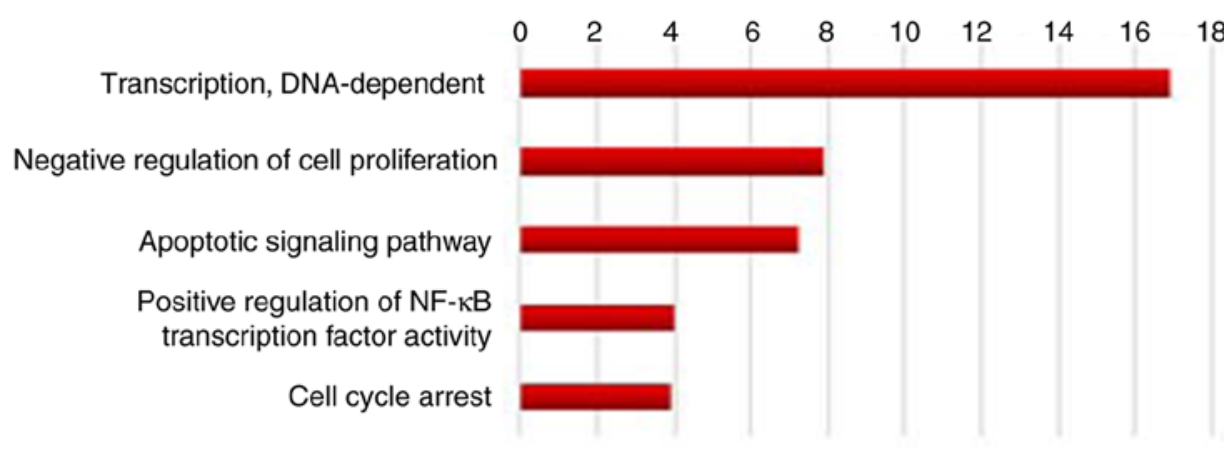

Dif gene Sig GO (-LgP)

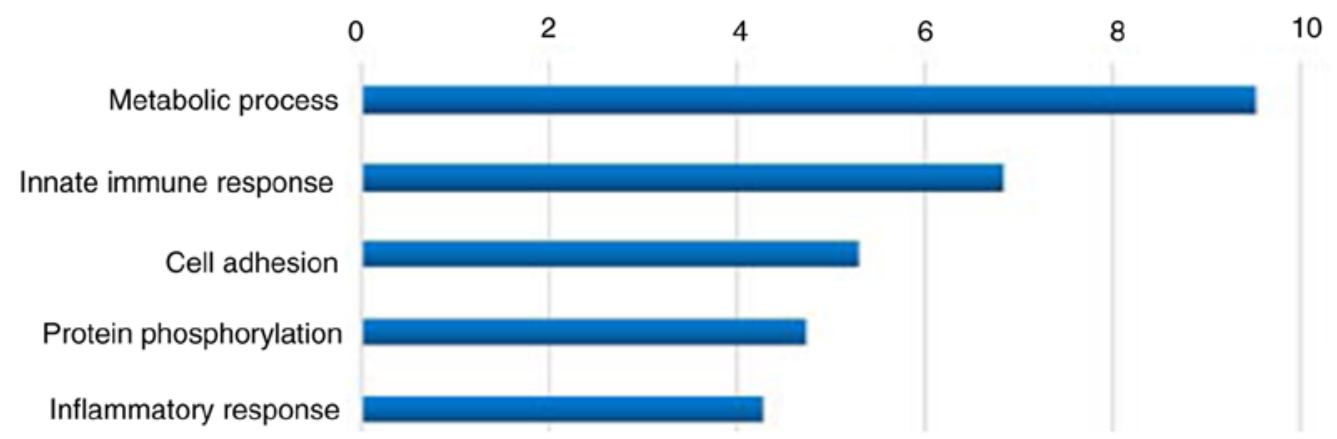

Figure 2. Gene expression profile analysis of IGF-IR knockdown in SKM-1 cells. (A) Pathway analysis revealed that the pathways significantly affected by genes upregulated in the IGF-IR knockdown cells, included MAPK signaling, apoptosis, transcriptional dysregulation in cancer, p53 signaling and Notch signaling, and the pathways significantly affected by downregulated genes in the knockdown cells included metabolism, insulin signaling, PI3K-Akt signaling and Toll-like receptor signaling. (B) GO analysis revealed that the ontologies significantly affected by upregulated genes in the knockdown cells included DNA-dependent transcription, negative regulation of cell proliferation, apoptosis signaling pathway, positive regulation of NF- $\mathrm{BB}$ transcriptional factor activity and cell cycle arrest, and the ontologies significantly affected by downregulated genes included metabolic processes, innate immunity, cell adhesion, protein phosphorylation and inflammatory response. 


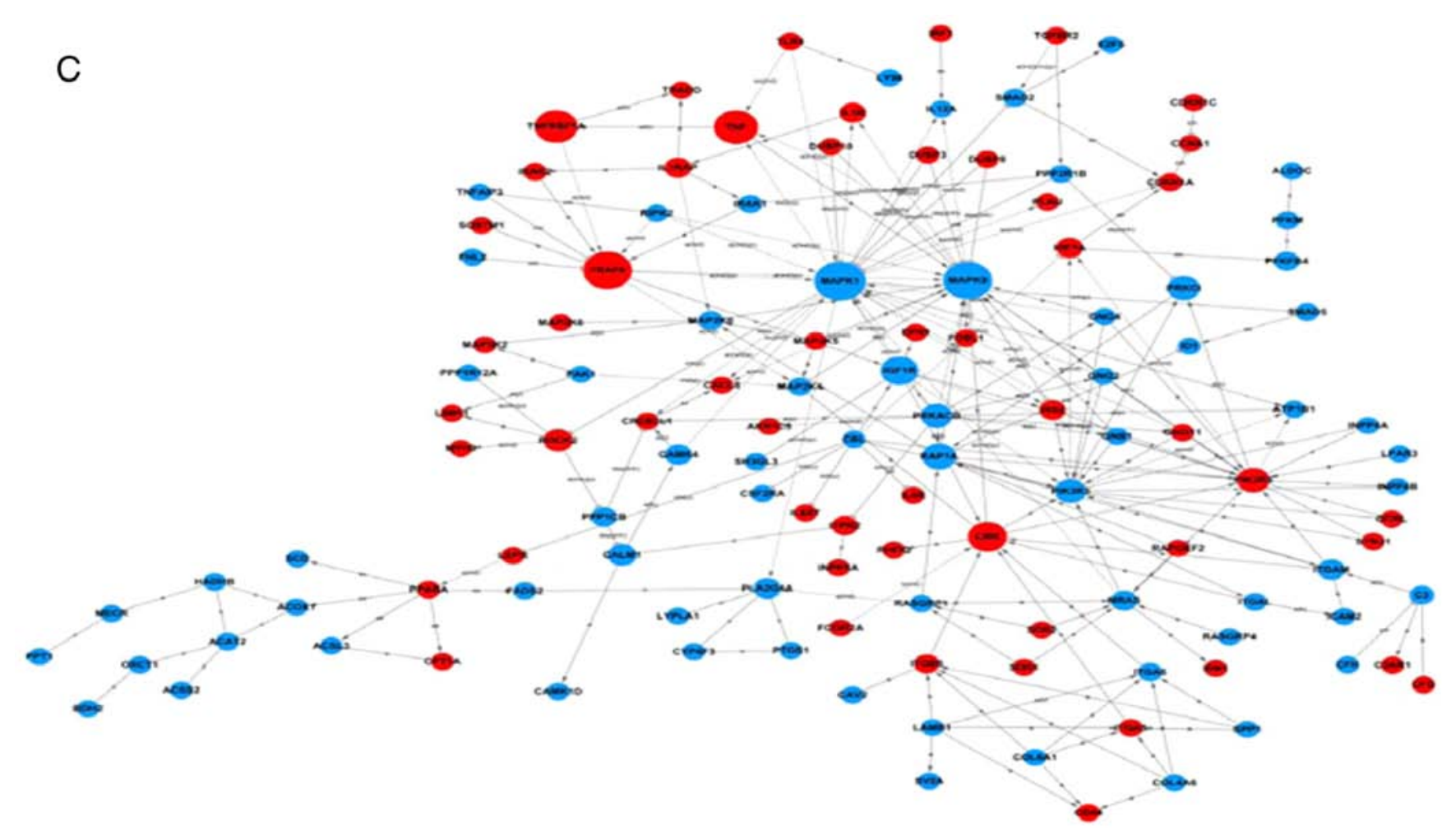

Figure 2. Continued. Gene expression profile analysis of IGF-IR knockdown in SKM-1 cells. (C) Further pathway-net analysis revealed that MAPK was a key node among genes downregulated as a result of IGF-IR knockdown, and the main upregulated genes were apoptosis-related pathway genes. IGF-IR, type 1 insulin-like growth factor receptor; GO, gene ontology.

The signal intensity was acquired using a GeneChip Scanner 3000 (Affymetrix; Thermo Fisher Scientific, Inc.) to generate cell intensity files. The statistical analysis was performed using Partek Genomics Suite software 7.0 (Partek, Inc.). Changes in expression $>2$-fold were considered relevant.

GO, pathway and pathway-net analyses of differentially expressed genes. Pathway and GO (Gene Oncology) enrichment analysis was used to determine significant pathways or ontology based on differential gene expression using Kyoto Encyclopedia of Genes and Genomes (KEGG) (www.kegg.jp) and GO resources (genontology.org). A Fisher's exact test was used to determine whether a pathway was significant, and the threshold of significance was defined by the P-value and False Discovery Rate. The Pathway-net (www.gminix.com) is the net interaction of the significant pathways of the differentially expressed genes, and was built according to the interaction amongst the pathways in the KEGG analysis. This approach summarizes and identifies the pathway interactions of genes differentially expressed in diseases.

Western blotting. SKM-1 and K562 cells $\left(\sim 1 \times 10^{7}\right)$ were lysed using cell lysis buffer (Cell Signaling Technology, Inc.). Protein concentrations were determined using a bicinchoninic acid assay kit (Beyotime Institute of Biotechnology). Equal quantities of total protein (30 $\mu \mathrm{g} / \mathrm{lane})$ were loaded on a $10 \%$ SDS-gel, resolved using SDS-PAGE, and transferred to PVDF membranes (EMD Millipore). The membranes were blocked with 5\% non-fat dry milk in diluted Tris-buffered saline with 0.1\% Tween-20 (cat. no. 9997; Cell Signaling Technology) for $1 \mathrm{~h}$ at room temperature and then were incubated overnight at $4^{\circ} \mathrm{C}$ in $5 \%$ non-fat dry milk with $0.1 \%$ Tween- 20 that contained one of the following primary antibodies: p38 MAPK, p-p38 MAPK, p44/42 MAPK, p-p44/42 MAPK, GSK, p-GSK, Akt, p-Akt or $\beta$-actin (dilution 1:1,000; Cell Signaling Technology). Horseradish peroxidase-conjugated antibodies to rabbit (cat. no. 7074; Cell Signaling Technology) or mouse (cat. no. 7076; Cell Signaling Technology) were used as the secondary antibody. The membranes were subsequently incubated with the corresponding secondary antibody for $1 \mathrm{~h}$ at room temperature. Signals were visualized using enhanced chemiluminescence method (product code 34577; Thermo Fisher Scientific, Inc.). An Epson Perfection 4490 Scanner was used to scan the films (EpsonEurope B.V.).

Statistical analysis. All statistical analysis was performed using SPSS version 11 (IBM, Corp.). Differences among groups were compared using an unpaired t-test or ANOVA test followed by Tukey's multiple comparisons test. Differences among percentages were compared using Chi-square test. All trials were repeated at least 3 times. $\mathrm{P}<0.05$ was considered to indicate a statistically significant difference.

\section{Results}

IGF-IR is required for the maintenance of clonal proliferation of MDS/leukemia cells. Transfection of MDS cells with IGF-IR shRNA lentivirus resulted in a decrease in IGF-IR expression in the SKM-1 (MDS-derived leukemia cell line) and K562 (acute erythroid leukemia cell line) cells (Figs. 1A and S1). To evaluate the proliferation dependence of tumor cells on IGF-IR, colony formation and CCK-8 proliferation assays were 


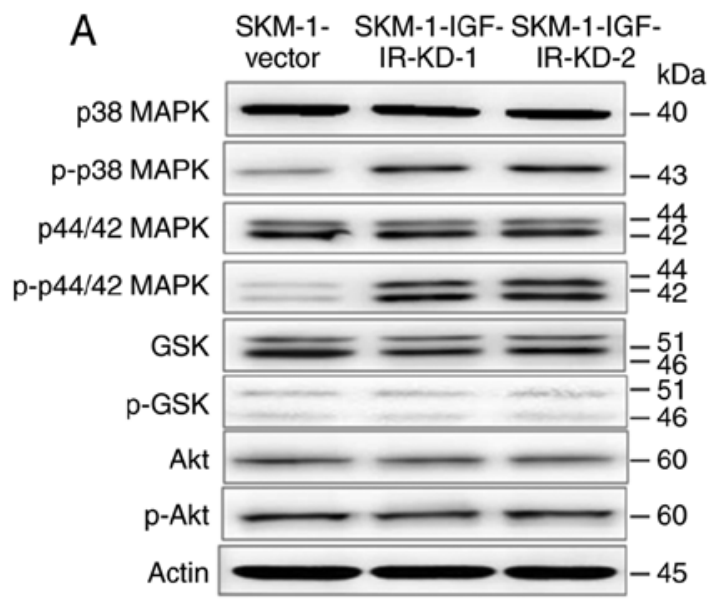

C

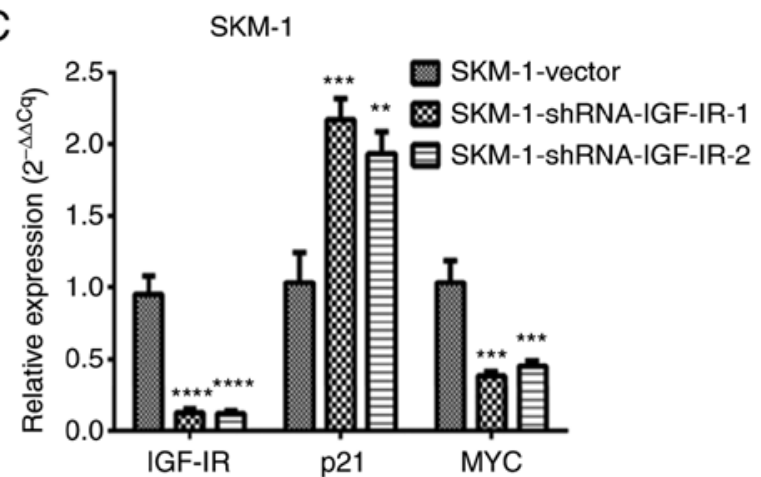

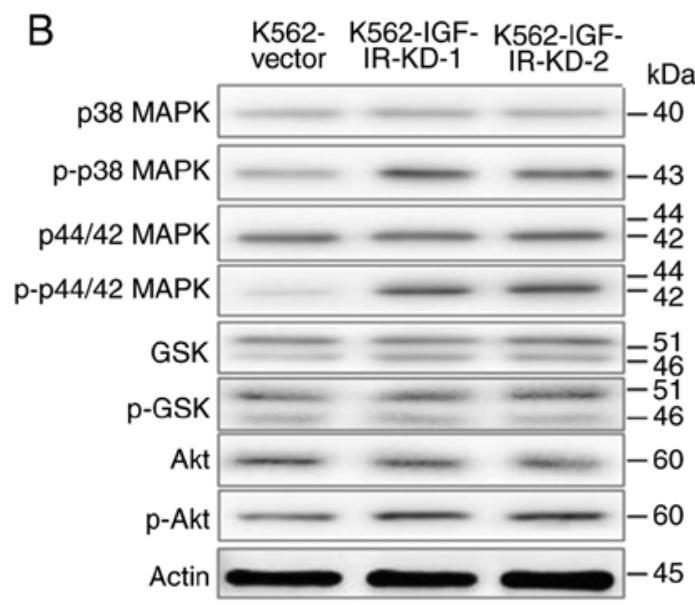

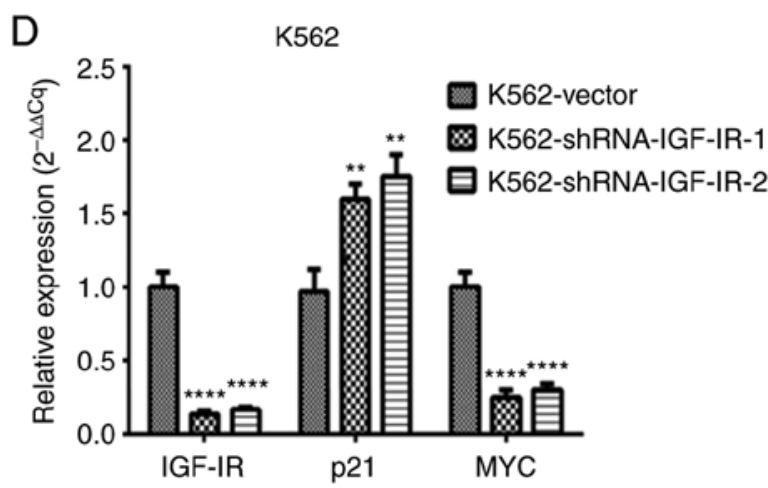

Figure 3. IGF-IR knockdown activates the MAPK signaling pathway in MDS/leukemia cell lines. Western blot analysis revealed that MAPK signaling characterized by p-p38 MAPK and p-p44/42 MAPK was activated by knockdown of IGF-IR in (A) SKM-1 and (B) K562 cells. p21 and MYC are considered critical target genes of the MAPK signaling pathway. IGF-IR knockdown increased the mRNA expression levels of (C) p21 whereas the expression of (D) MYC was decreased. ${ }^{* *} \mathrm{P}<0.01,{ }^{* * *} \mathrm{P}<0.001,{ }^{* * * * *} \mathrm{P}<0.0001$ (ANOVA). IGF-IR, type 1 insulin-like growth factor receptor; p-, phosphorylated; MDS, myelodysplastic syndrome; shRNA, short hairpin RNA; KD, knockdown.

performed. The colony formation assays revealed that SKM-1 and K562 cells with IGF-IR knockdown significantly reduced colony formation compared with the control cells (Fig. 1A). CCK-8 assays revealed that knockdown of IGF-IR inhibited cell growth compared with the control cells (Fig. 1B). The apoptosis rate was determined using flow cytometry, and the mean apoptotic rate was significantly higher in SKM-1 and K562 cells with IGF-IR knockdown compared with the control cells (Figs. 1C and S2). Collectively, these data indicated that IGF-IR was required for the maintenance of malignant proliferation of MDS/leukemia cells.

Identification of IGF-IR-associated signaling pathways based on GEM and bioinformatic analyses. To determine the mechanism by which IGF-IR regulated the proliferation of MDS clonal cells, gene expression profiling on SKM-1 cells with IGF-IR-knockdown $(n=3)$ and control cells $(n=3)$ was performed. Gene expression profiling identified 1,654 differentially expressed genes (954 downregulated genes and 700 upregulated genes). Gene Ontology (GO) analysis of these genes was also performed. The results of pathway analysis revealed that the pathways significantly affected by upregulated genes, included MAPK signaling, apoptosis, transcriptional dysregulation in cancer, p53 signaling, and Notch signaling (all $\mathrm{P}<0.001$ ), and the pathways significantly affected by downregulated genes included metabolism, insulin signaling, PI3K-Akt signaling and Toll-like receptor signaling $(\mathrm{P}<0.01)$ (Fig. 2A). The results of GO analysis revealed that the ontologies significantly affected by upregulated genes included DNA-dependent transcription, negative regulation of cell proliferation, apoptosis signaling pathway, positive regulation of NF- $\kappa \mathrm{B}$ transcriptional factor activity and cell cycle arrest (all $\mathrm{P}<0.001$ ), and the ontologies significantly affected by downregulated genes included metabolic processes, innate immunity, cell adhesion, protein phosphorylation and inflammatory response $(\mathrm{P}<0.001)$ (Fig. $2 \mathrm{~B})$. Further pathway-net analysis revealed that MAPK was a key node among the downregulated genes as a result of IGF-IR knockdown, and the primary upregulated genes were apoptosis-associated pathway genes (Fig. 2C). Collectively, the results indicated that knockdown of IGF-IR resulted in abnormal MAPK signaling, which may underlie the dysregulated cell proliferation and apoptosis.

Knockdown of IGF-IR activates the MAPK signaling pathway in MDS/leukemia cells. In order to validate the results of gene expression microarray and bioinformatics analysis, expression of specific key signaling pathway proteins associated with hematological diseases was determined using western blotting and RT-qPCR. The results determined the expression levels of relevant proteins. It was revealed that MAPK signaling characterized by p-p38 

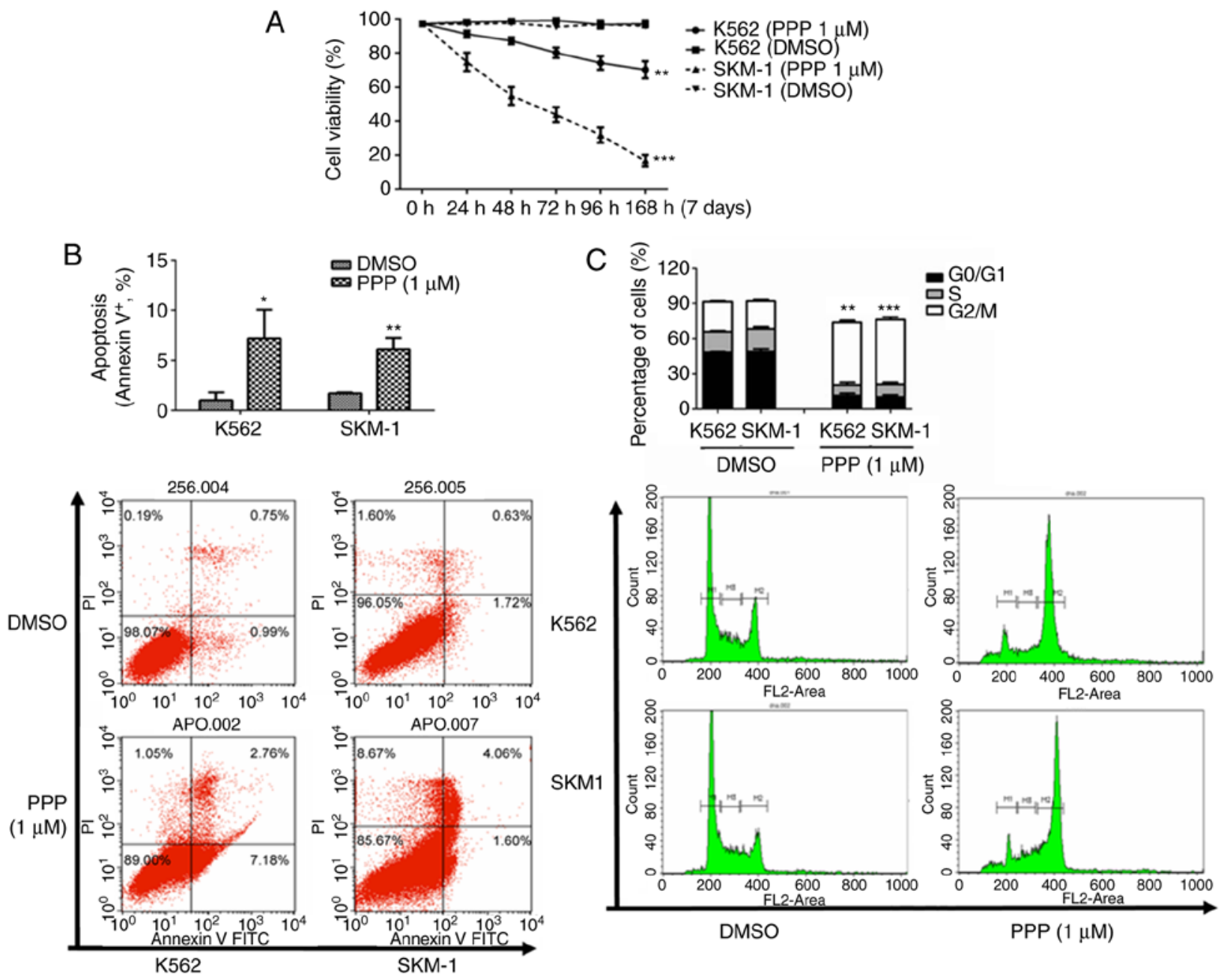

Figure 4. PPP inhibits proliferation, promotes apoptosis and induces cell cycle arrest at the G2/M phase in MDS/leukemia cell lines. (A) PPP inhibited proliferation of both SKM-1 and K562 cell lines. The mean cell viability of SKM-1 cells was reduced from 97.2 to $16.6 \%$, and the mean cell viability of K562 cell reduced from 97.1 to $70.3 \%$. (B) PPP promoted apoptosis. The mean apoptotic rate of the SKM-1 cell line increased from 1.7 to $6.2 \%$, and the mean apoptotic rate of the K562 cell line increased from 1.0 to $7.2 \%$. ${ }^{*} \mathrm{P}<0.05,{ }^{* *} \mathrm{P}<0.01$ (unpaired t-test). (C) PPP significantly induced G2/M phase block and decreased the percentage of cells in the S phase in SKM-1 and K562 cells. M1 represents G0/G1 phase cells, M2 represents S phase cells, M3 represents G2/M phase cells, and M1-M3 was flanked by fragments and clumps of cells, thus, the sum of the three was $<100 \%$. ${ }^{* *} \mathrm{P}<0.01,{ }^{* * * *} \mathrm{P}<0.001$ (Chi-square test). PPP, picropodophyllin; MDS, myelodysplastic syndrome.

MAPK and p-p44/42 MAPK was activated by knockdown of IGF-IR in SKM-1 and K562 cells (Fig. 3A and B). p21 and MYC are considered critical target genes of MAPK signaling. The knockdown of IGF-IR increased the expression of $\mathrm{p} 21$ whereas the expression of MYC was decreased (Fig. 3C and D). Knockdown of IGF-IR activated the MAPK signaling pathway, which may lead to an increase in the expression of the pro-apoptotic gene $\mathrm{p} 21$, and a decrease in the pro-proliferative gene MYC.

Effect of IGF-IR inhibitor PPP on the properties of MDS/leukemia cells in vitro. In order to examine whether IGF-IR may serve as a therapeutic target for treatment of MDS, PPP, an IGF-IR specific inhibitor was used. PPP was added to the two cell lines SKM-1 and K562, whereas an equivalent volume of DMSO was added to the control group. Cells were harvested after treatment with PPP for 0, 24, 48, 72, 96 and $168 \mathrm{~h}$, and Trypan blue staining was performed. The number of viable cells was counted, and cell viability was calculated. The cell viability of the two cell lines was reduced in a time-dependent manner. The mean cell viability of SKM-1 cells was reduced from 97.2 to $16.6 \%(\mathrm{P}<0.001)$, and the mean cell viability of K562 cells was reduced from 97.1 to $70.3 \%$ ( $\mathrm{P}=0.007$ ) (Fig. $4 \mathrm{~A}$ ). The apoptotic rate was determined using flow cytometry and it was revealed that PPP induced cell apoptosis in vitro. The mean apoptotic rate of SKM-1 cells was increased from 1.7 to $6.2 \%(\mathrm{P}=0.002)$, and the mean apoptotic rate of K562 cells increased from 1.0 to 7.2\% ( $\mathrm{P}=0.024)$ (Fig. 4B). In addition, it was also determined that PPP significantly induced arrest of the cell cycle at the $\mathrm{G} 2 / \mathrm{M}$ phase and decreased the percentage of cells in the $\mathrm{S}$ phase in SKM-1 and K562 cells (Fig. 4C).

Effect of PPP on the properties of $\mathrm{CD} 34^{+}$cells obtained from patients with MDS. The purity of positive CD34 cells sorted by MACS was $\sim 90 \%$. Treatment with PPP significantly reduced the cell viability of $\mathrm{CD} 34^{+}$cells of the 8 patients with MDS. Averaging the viability across all 8 groups of cells, the mean cell viability was reduced from 84.2 to $67.1 \%$. Additionally, proliferation was also significantly reduced following treat- 
A

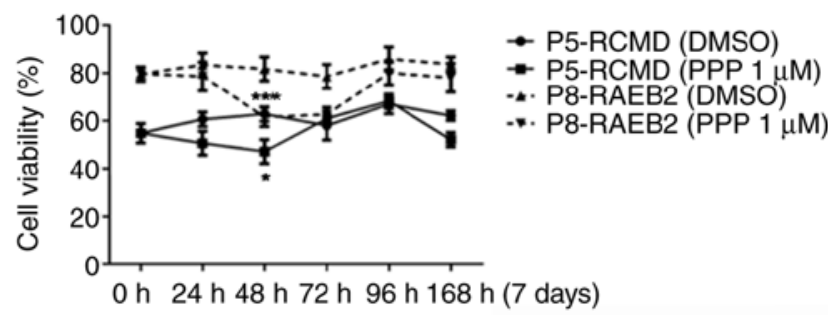

B

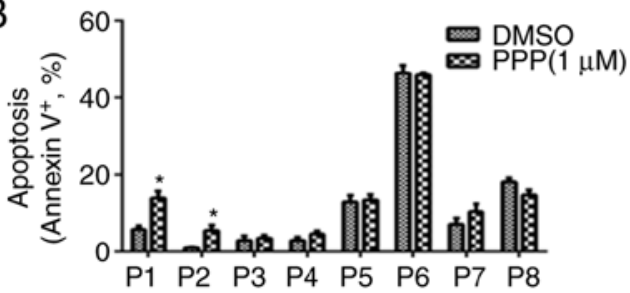

C

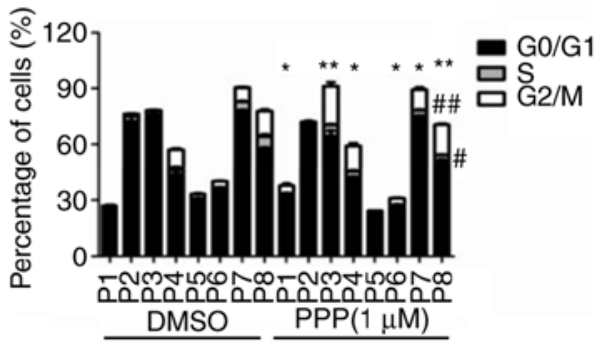

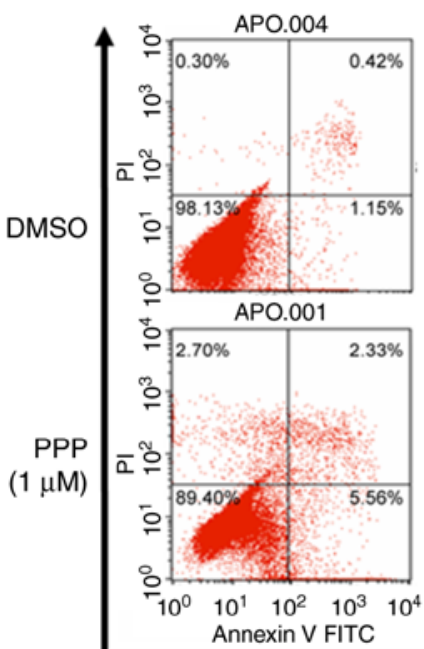

RAEB1
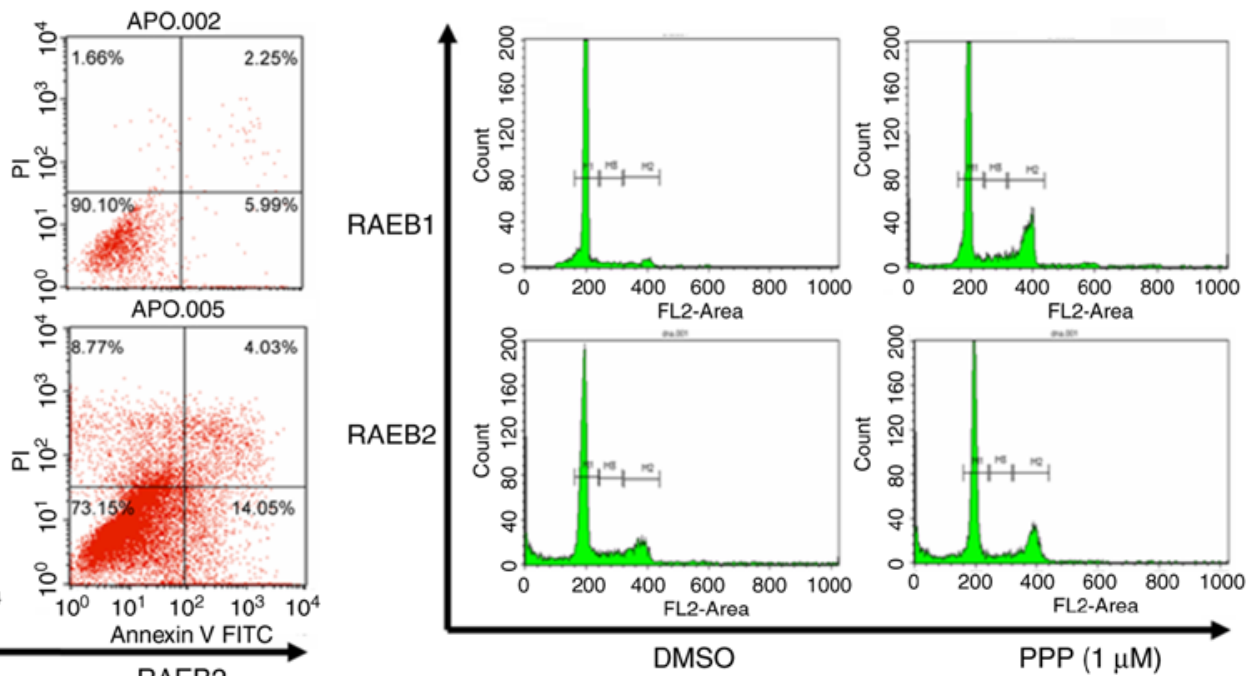

Figure 5. PPP inhibits proliferation, promotes apoptosis and induces cell cycle arrest in G2/M in CD34 ${ }^{+}$cells of patients with MDS. (A) Following PPP treatment, cell viability of CD34 $4^{+}$cells of 8 patients with MDS was also significantly reduced. Collectively, the mean cell viability was reduced from 84.2 to $67.1 \%$. The decrease in proliferation was the most significant, decreasing to $60.1 \%$ after $48 \mathrm{~h}$ of treatment, after which proliferation increased to varying degrees in the different groups of cells obtained from patients. Representative graphs for two patients (RCMD and RAEB2) are presented. (B) PPP increased apoptosis in the CD34+ cells of 6 MDS patients, among which the differences of 2 patients were statistically significant. "P<0.05 (unpaired t-test). (C) The cell cycles of the $\mathrm{CD}_{3} 4^{+}$cells of 7 MDS patients were arrested in the G2/M phase when treated with PPP. The percentage of cells in the S-phase in 5 patients was reduced, among which the reduction in patients no. 7 and 8 were the most significant. M1 represents G0/G1 phase cells, M2 represents S phase cells, M3 represents G2/M phase cells, and M1-M3 was flanked by fragments and clumps of cells, thus, the sum of the three was $<100 \%$. "P $<0.05,{ }^{* * *} \mathrm{P}<0.01$ vs. the G2/M phase; ${ }^{\#} \mathrm{P}<0.05,{ }^{\# \prime} \mathrm{P}<0.01$ vs. the $\mathrm{S}$ phase (Chi-square test). PPP, picropodophyllin; MDS, myelodysplastic syndrome.

ment with PPP to $60.1 \%$ after $48 \mathrm{~h}$ of drug treatment $(\mathrm{P}=0.003)$. When cells were treated for time periods longer than $48 \mathrm{~h}$, proliferation appeared to increase. Individually, inhibition of cell proliferation was most significant in the 8 patients after either 48 or $72 \mathrm{~h}$ of drug treatment. Thereafter, proliferation exhibited varying degrees of recovery, and the proliferation in the cells obtained from certain patients recovered to pre-treatment levels. Cell viability before and after drug treatment of each patient was compared with the lowest level of proliferation, respectively, and the differences were found to be statistically significant (Fig. 5A; Tables I and SII). PPP increased the rate of apoptosis in the CD34+ cells of $6 \mathrm{MDS}$ patients, of which, the differences of 2 patients were statistically significant (Fig. 5B). The cell cycles of the CD34+ cells of $7 \mathrm{MDS}$ patients were arrested in the G2/M phase, among which the differences of 6 patients were statistically signifi- cant. The percentage of cells in the S-phase of 5 patients was reduced, among which the reduction in the S-phase in nos. 7 and 8 were the most significant, and the differences were statistically significant (Fig. 5C).

PPP activates the MAPK signaling pathway in MDS/leukemia cells. As aforementioned, IGF-IR knockdown activated the MAPK signaling pathway in SKM-1 and K562 cells. As an inhibitor of IGF-IR, the effect of PPP on MAPK was investigated to validate the data from IGF-IR knockdown. PPP upregulated the expression of MAPK signaling-related proteins including p-p38 MAPK and p-p44/42 MAPK in SKM-1 cells (Fig. 6A). PPP also increased the expression of p-p44/42 MAPK, whereas the expression of p-p38 MAPK in K562 cells was not altered, possibly due to characteristics of the cell line and the specific effects of PPP on this cell line 

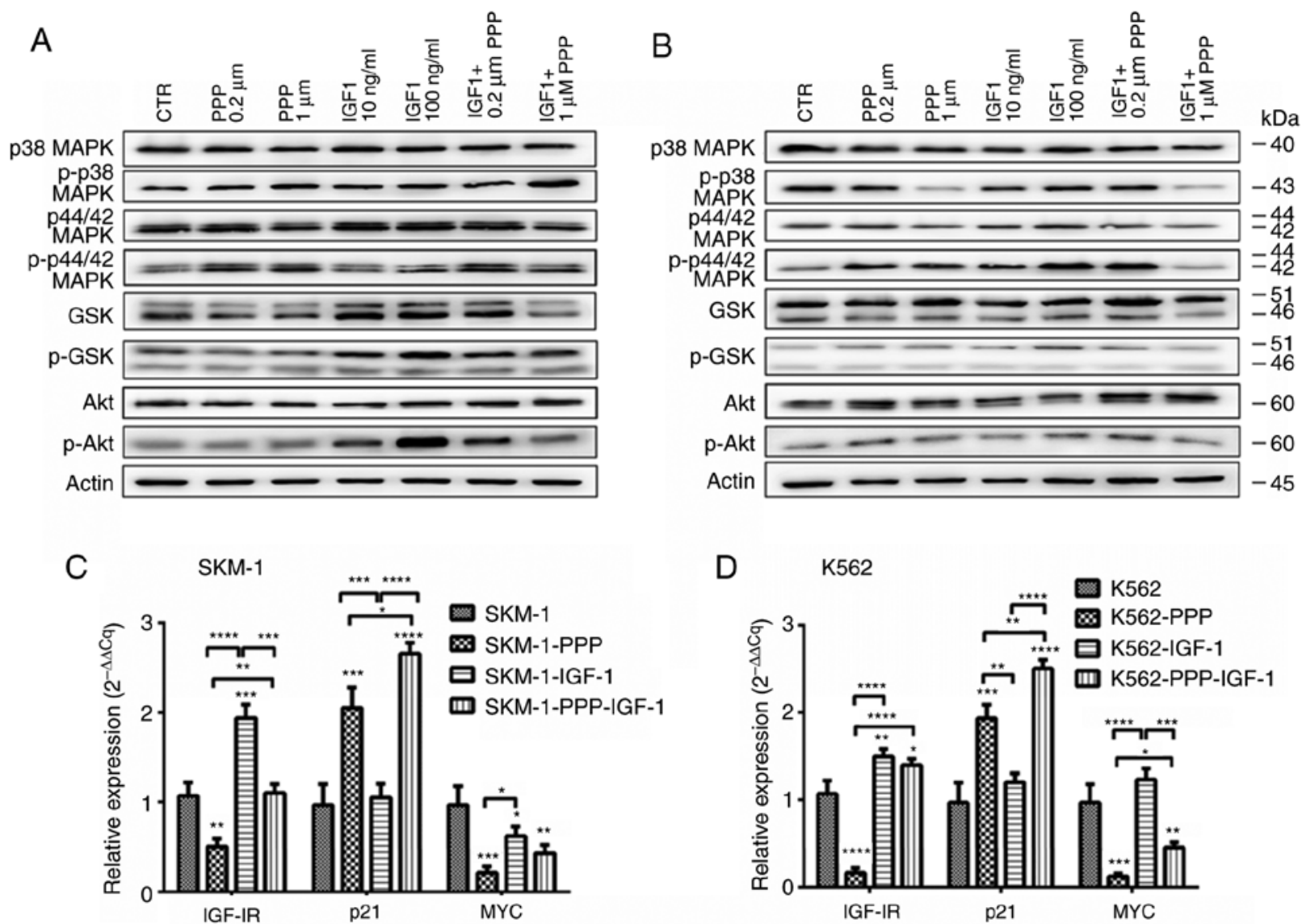

Figure 6. PPP activates the MAPK signaling pathway in MDS/leukemia cell lines. (A) Western blot analysis revealed that treatment with PPP upregulated the expression of MAPK signaling-related proteins including p-p38 MAPK and p-p44/42 MAPK in SKM-1 cells. (B) PPP increased the expression of p-p44/42 MAPK whereas the expression of p-p38 MAPK in K562 cells was not altered. (C and D) PPP increased the mRNA expression levels of p21 and inhibited the expression of MYC in SKM-1 and K562 cells. ${ }^{*} \mathrm{P}<0.05,{ }^{* *} \mathrm{P}<0.01,{ }^{* * * *} \mathrm{P}<0.001,{ }^{* * * *} \mathrm{P}<0.0001$ (ANOVA). PPP, picropodophyllin; MDS, myelodysplastic syndrome; p-, phosphorylated; IGF-IR, type 1 insulin-like growth factor receptor.

(Fig. 6B). PPP increased the expression of p21 and reduced the expression of MYC (Fig. 6C and D). Collectively, PPP may be considered a potential therapeutic agent for treatment of MDS.

\section{Discussion}

Numerous studies have used genome sequencing technologies to study MDS bone marrow cells, and IGF-IR mutations have not been identified as of yet, to the best of our knowledge (29-31). Similarly, IGF-IR mutations have not been identified in solid tumor cells (32). However, our previous studies revealed that the high expression of IGF-IR was mainly in MDS clonal cells $(19,20)$, suggesting that the changes in IGF-IR gene expression levels may be associated with the pathogenesis of MDS, thereby regulating the proliferation of MDS clonal cells.

In order to study the mechanism by which IGF-IR regulates MDS clonal cell proliferation, RNA interference was used to knockdown IGF-IR in SKM-1 and K562 cell lines in vitro, and the changes in the biological activity of the cells was assessed. The results demonstrated that cell proliferation rates of SKM-1 and K562 cell lines following IGF-IR knockdown were significantly reduced, and the apoptotic rates were significantly increased. This suggests that the downregulation of IGF-IR may inhibit the proliferation of MDS/leukemia cell lines and induce apoptosis. These results are consistent with the results reported on IGF-IR in other types of solid tumors $(9,10,32)$. The results of the gene expression profile and pathway-net analysis of SKM-1 cells with IGF-IR knockdown indicated that the downregulation of IGF-IR resulted in abnormalities in MAPK signaling, apoptosis as well as other signaling pathways, thereby leading to abnormal cell proliferation and apoptosis. Subsequently, western blotting was used to confirm that IGF-IR knockdown resulted in a significant increase in the expression of two proteins, p-p38 MAPK and p-p44/42 MAPK, indicating that IGF-IR primarily regulated the proliferative and anti-apoptotic activities of MDS/leukemia cell lines via inhibition of the MAPK signaling pathway. p21 and MYC are considered critical target genes of MAPK signaling $(33,34)$. The results of the mRNA changes in p21 and MYC confirmed that the MAPK pathway was activated. Although the majority of studies have demonstrated that the p-p44/42 MAPK pathway exerts an anti-apoptotic role, p-p44/42 MAPK signaling has also been demonstrated to exhibit a pro-apoptotic effect, such as in neurons (35), platelets (36) and cardiomyocytes (37). Studies have demonstrated that overactivation of MAPK and TGF- $\beta$ signaling pathways in low-risk MDS can promote excessive apoptosis of hematopoietic stem cells, whereas the AKT/PI3K, PI3K/mTOR and EGF signaling pathways are overactivated in high-risk MDS (38-41). In the present study, the inhibitory effects of 
IGF-IR on the MAPK signaling pathway may also serve an important role in high-risk MDS.

The results of the aforementioned in vitro experiments revealed that IGF-IR may serve as an oncogene in regulating the proliferation of MDS clonal cells. To further clarify whether IGF-IR could be used as a novel therapeutic target for treatment of MDS, a specific inhibitor of IGF-IR was used to perform intervention experiments in the primary MDS cells to observe the changes in the biological activity of these cells. PPP is an IGF-IR-specific tyrosine kinase inhibitor that can specifically reduce the phosphorylation of tyrosine residue Y1136 of IGF-IR, and thus inhibit the activity of IGF-IR, without affecting the activity of IR (9). PPP (clinical drug name is AXL1717) $(42,43)$ is currently undergoing phase I/II clinical trials, and the existing data demonstrated that PPP has multiple clinical efficacies with only mild side effects. In the present study, PPP was used to treat cells in vitro in two cell lines (SKM-1 and K562,) and primary CD34+ cells isolated from 8 patients with MDS, and it was revealed that cell proliferation was significantly inhibited. However, the proliferation of $\mathrm{CD} 4^{+}$cells from MDS patients gradually recovered after 48 or $72 \mathrm{~h}$ of PPP treatment, which may be associated with the heterogeneity of $\mathrm{CD} 34^{+}$cells (such as the co-existence of normal cells and clonal cells in $\mathrm{CD} 34^{+}$cells from MDS patients). After treatment with PPP, the apoptotic rates of the two cell lines and $\mathrm{CD} 34^{+}$cells from 4 of the patients with MDS were significantly increased, whereas the apoptotic rates of $\mathrm{CD} 34^{+}$cells from the other 4 patients with MDS were not significantly altered, although the number of dead cells significantly increased. Furthermore, following treatment with PPP, the cell cycles of the cell lines and $\mathrm{CD} 34^{+}$cells from 7 of the MDS patients were arrested in the $\mathrm{G} 2 / \mathrm{M}$ phase, and the majority of the cells also exhibited a significant decrease in the percentage of cells in the S-phase. Collectively, this indicated that inhibition of IGF-IR activity using PPP resulted in a reduction in DNA synthesis and cell cycle arrest, thus significantly reducing the number of cells entering cell division. This result was consistent with that induced by knockdown of IGF-IR using RNA interference. Recently, the effect of IGF-IR inhibitors on acute lymphoblastic cell lines was studied (44), and the results suggested that OSI-906 (IGF-IR/IR inhibitor) inhibited ERK activation, and NT157 (IGF-IR-IRS1/2 inhibitor) induced ERK activation. Although their targets were different from PPP, they all affected the MAPK signaling pathway. Different drugs have different effects on the MAPK signaling pathway, and to complicate matters further the same drug, such as PPP, may exhibit varying effects on the MAPK signaling pathway in different cell lines based on the results of the present study. Collectively, this highlights the complexity of the mechanisms of inhibitors.

In conclusion, knockdown of IGF-IR activity using RNA interference or with a specific inhibitor inhibited proliferation and induced apoptosis in MDS cells, either in established cell lines or primary cultured cells isolated from MDS patients, thus resulting in arrest of the cell cycle. IGF-IR may promote MDS cell proliferation, and inhibit apoptosis primarily through inhibition of the MAPK signaling pathway. IGF-IR thus may serve as a potential therapeutic target for treatment of MDS.

\section{Acknowledgements}

We thank Shanghai Qiming, Inc. for providing assistance in the bioinformatics analysis.

\section{Funding}

The present study was funded by the National Natural Science Foundation of China (nos. 81100341, 81570108 and 81400090).

\section{Availability of data and materials}

The datasets supporting the conclusions of this article are included within this article and its additional images. Raw data are available from the corresponding author on reasonable request.

\section{Authors' contributions}

QH, QZ, CC and FX performed all the experiments. QH and QZ cultured the cells and performed the RT-qPCR and western blotting. QH and FX wrote the manuscript. WS and JG performed the flow cytometric analysis. ZZ and SZ collected the bone marrow samples of patients. QH and QZ performed the statistical analysis. XL conceived the study and participated in its design. All authors read and approved the final manuscript.

\section{Ethics approval and consent to participate}

The present study was approved by the Ethics Committee of the Sixth Hospital Affiliated with Shanghai Jiao Tong University, and all patients provided informed consent for the utilization of their tissue samples in this study.

\section{Patient consent for publication}

Not applicable.

\section{Competing interests}

The authors declare that they have no competing interests.

\section{References}

1. Tiu R, Gondek L, O'Keefe C and Maciejewski JP: Clonality of the stem cell compartment during evolution of myelodysplastic syndromes and other bone marrow failure syndromes. Leukemia 21: 1648-1657, 2007.

2. Steensma DP, Bejar R, Jaiswal S, Lindsley RC, Sekeres MA, Hasserjian RP and Ebert BL: Clonal hematopoiesis of indeterminate potential and its distinction from myelodysplastic syndromes. Blood 126: 9-16, 2015.

3. Qi H, Qingxia Z, Xiao L, Lingyun W, Feng X, Zheng Z and Chunkang C: Recurrent abnormal clones in myelodysplastic syndrome marrow originate from cells at a pluripotent stem level and maintain their early differentiation potency. Cancer Invest 33: 369-377, 2015.

4. Smith MA, Choudhary GS, Pellagatti A, Choi K, Bolanos LC, Bhagat TD, Gordon-Mitchell S, Von Ahrens D, Pradhan K, Steeples V, et al: U2AF1 mutations induce oncogenic IRAK4 isoforms and activate innate immune pathways in myeloid malignancies. Nat Cell Biol 21: 640-650, 2019.

5. Kennedy AL and Shimamura A: Genetic predisposition to MDS: Clinical features and clonal evolution. Blood 133: 1071-1085, 2019. 
6. Nolte F and Hofmann WK: Molecular mechanisms involved in the progression of myelodysplastic syndrome. Future Oncol 6: 445-455, 2010.

7. Issa JP: Epigenetic changes in the myelodysplastic syndrome. Hematol Oncol Clin North Am 24: 317-330, 2010.

8. Zhang Z, Zhao L, Wei X, Guo Q, Zhu X, Wei R, Yin X, Zhang Y, Wang B and Li X: Integrated bioinformatic analysis of microarray data reveals shared gene signature between MDS and AML. Oncol Lett 16: 5147-5159, 2018.

9. Gao J, Chang YS, Jallal B and Viner J: Targeting the insulin-like growth factor axis for the development of novel therapeutics in oncology. Cancer Res 72: 3-12, 2012.

10. Guerreiro AS, Boller D, Doepfner KT and Arcaro A: IGF-IR: Potential role in antitumor agents. Drug News Perspect 19: 261-272, 2006

11. Strömberg T, Ekman S, Girnita L, Dimberg LY, Larsson O, Axelson M, Lennartsson J, Hellman U, Carlson K, Osterborg A, et al: IGF-1 receptor tyrosine kinase inhibition by the cyclolignan PPP induces G2/M-phase accumulation and apoptosis in multiple myeloma cells. Blood 107: 669-678, 2006.

12. Tazzari PL, Tabellini G, Bortul R, Papa V, Evangelisti C, Grafone T, Martinelli G, McCubrey JA and Martelli AM The insulin-like growth factor-I receptor kinase inhibitor NVP-AEW541 induces apoptosis in acute myeloid leukemia cells exhibiting autocrine insulin-like growth factor-I secretion. Leukemia 21: 886-896, 2007.

13. Shi P, Chandra J, Sun X, Gergely M, Cortes JE, Garcia-Manero G, Arlinghaus RB, Lai R and Amin HM: Inhibition of IGF-IR tyrosine kinase induces apoptosis and cell cycle arrest in imatinib-resistant chronic myeloid leukaemia cells. J Cell Mol Med 14: 1777-1792, 2010.

14. Whelan JT, Ludwig DL and Bertrand FE: HoxA9 induces insulin-like growth factor-1 receptor expression in B-lineage acute lymphoblastic leukemia. Leukemia 22: 1161-1169, 2008.

15. Schillaci R, Galeano A, Becu-Villalobos D, Spinelli O, Sapia S and Bezares RF: Autocrine/paracrine involvement of insulin-like growth factor-I and its receptor in chronic lymphocytic leukaemia. Br J Haematol 130: 58-66, 2005.

16. Malaguarnera $\mathrm{R}$ and Belfiore $\mathrm{A}$ : The emerging role of insulin and insulin-like growth factor signaling in cancer stem cells Front Endocrinol (Lausanne) 5: 10, 2014.

17. Muraguchi T, Nanba D, Nishimura EK and Tashiro T: IGF-1R deficiency in human keratinocytes disrupts epidermal homeostasis and stem cell maintenance. J Dermatol Sci 94: 298-305, 2019.

18. Teng CF, Jeng LB and Shyu WC: Role of insulin-like growth factor 1 receptor signaling in stem cell stemness and therapeutic efficacy. Cell Transplant 27: 1313-1319, 2018

19. Qi H, Xiao L, Lingyun W, Ying T, Yi-Zhi L, Shao-Xu Y and Quan P: Expression of type 1 insulin-like growth factor receptor in marrow nucleated cells in malignant hematological disorders: Correlation with apoptosis. Ann Hematol 85: 95-101, 2006.

20. He Q, Li X, Zhang Z, Zhang Q, Xu F, Yang L, Tao Y and Liu Y: Overexpression of IGF-IR in malignant clonal cells in bone marrow of myelodysplastic syndromes. Cancer Invest 28 983-988, 2010

21. He Q, Chang CK, Xu F, Zhang QX, Shi WH and Li X: Purification of bone marrow clonal cells from patients with myelodysplastic syndrome via IGF-IR. PLoS One 10: e0140372, 2015.

22. Valent P, Horny HP, Bennett JM, Fonatsch C, Germing U, Greenberg P, Haferlach T, Haase D, Kolb HJ, Krieger O, et al: Definitions and standards in the diagnosis and treatment of the myelodysplastic syndromes: Consensus statements and report from a working conference. Leuk Res 31: 727-736, 2007.

23. Vardiman JW, Harris NL and Brunning RD: The world health organization (WHO) classification of the myeloid neoplasms. Blood 100: 2292-2302, 2002

24. Delacrétaz F, Schmidt PM, Piguet D, Bachmann F and Costa J: Histopathology of myelodysplastic syndromes. The FAB classification (proposals) applied to bone marrow biopsy. Am J Clin Pathol 87: 180-186, 1987

25. Greenberg P, Cox C, LeBeau MM, Morel P, Sanz G, Sanz M, Vallespi T, Hamblin T, Oscier D, Ohyashiki K, et al: International scoring system for evaluating prognosis in myelodysplastic syndromes. Blood 89: 2079-2088, 1997.

26. Shaffer LG and Tommerup N (eds): ISCN: An international system for human cytogenetics nomenclature. (S Karger, Basel 2005), 2005
27. Nakagawa T, Matozaki S, Murayama T, Nishimura $R$ Tsutsumi M, Kawaguchi R, Yokoyama Y, Hikiji K, Isobe T and Chihara K: Establishment of a leukaemic cell line from a patient with acquisition of chromosomal abnormalities during disease progression in myelodysplastic syndrome. Br J Haematol 85: 469-476, 1993

28. Livak KJ and Schmittgen TD: Analysis of relative gene expression data using real-time quantitative PCR and the 2(-Delta Delta C(T)) method. Methods 25: 402-408, 2001

29. Hosono N: Genetic abnormalities and pathophysiology of MDS Int J Clin Oncol 24: 885-892, 2019.

30. Xu F, Wu LY, Chang CK, He Q, Zhang Z, Liu L, Shi WH, Guo J, Zhu Y, Zhao YS, et al: Whole-exome and targeted sequencing identify ROBO1 and ROBO2 mutations as progression-related drivers in myelodysplastic syndromes. Nat Commun 6: 8806, 2015.

31. Gonçalves AC, Alves R, Baldeiras I, Cortesão E, Carda JP, Branco CC, Oliveiros B, Loureiro L, Pereira A, Nascimento Costa JM, et al: Genetic variants involved in oxidative stress, base excision repair, DNA methylation, and folate metabolism pathways influence myeloid neoplasias susceptibility and prognosis. Mol Carcinog 56: 130-148, 2017.

32. Yuen JS and Macaulay VM: Targeting the type 1 insulin-like growth factor receptor as a treatment for cancer. Expert Opin Ther Targets 12: 589-603, 2008.

33. Narla G, Sangodkar J and Ryder CB: The impact of phosphatases on proliferative and survival signaling in cancer. Cell Mol Life Sci 75: 2695-2718, 2018

34. Xu Y, Li N, Xiang R and Sun P: Emerging roles of the p38 MAPK and PI3K/AKT/mTOR pathways in oncogene-induced senescence. Trends Biochem Sci 39: 268-276, 2014.

35. Li Q, Chen M, Liu H, Yang L, Yang T and He G: The dual role of ERK signaling in the apoptosis of neurons. Front Biosci (Landmark Ed) 19: 1411-1417, 2014.

36. Paul M, Manikanta K, Hemshekhar M, Sundaram MS, Naveen S, Ramesh TN, Kemparaju Kand Girish KS: Bisdemethoxycurcumin promotes apoptosis in human platelets via activation of ERK signaling pathway. Toxicol In Vitro 63: 104743, 2019.

37. Zhang DX, Ma DY, Yao ZQ, Fu CY, Shi YX, Wang QL and Tang QQ: ERK1/2/p53 and NF- $\kappa$ B dependent-PUMA activation involves in doxorubicin-induced cardiomyocyte apoptosis. Eur Rev Med Pharmacol Sci 20: 2435-2442, 2016.

38. Navas TA, Mohindru M, Estes M, Ma JY, Sokol L, Pahanish P, Parmar S, Haghnazari E, Zhou L, Collins R, et al: Inhibition of overactivated p38 MAPK can restore hematopoiesis in myelodysplastic syndrome progenitors. Blood 108: 4170-4177, 2006.

39. Bhagat TD, Zhou L, Sokol L, Kessel R, Caceres G, Gundabolu K, Tamari R, Gordon S, Mantzaris I, Jodlowski T, et al: miR-21 mediates hematopoietic suppression in MDS by activating TGF- $\beta$ signaling. Blood 121: 2875-2881, 2013.

40. Follo MY, Mongiorgi S, Bosi C, Cappellini A, Finelli C, Chiarini F, Papa V, Libra M, Martinelli G, Cocco L and Martelli AM: The Akt/mammalian target of rapamycin signal transduction pathway is activated in high-risk myelodysplastic syndromes and influences cell survival and proliferation. Cancer Res 67: 4287-4294, 2007.

41. Boehrer S, Adès L, Braun T, Galluzzi L, Grosjean J, Fabre C, Le Roux G, Gardin C, Martin A, de Botton S, et al: Erlotinib exhibits antineoplastic off-target effects in AML and MDS: A preclinical study. Blood 111: 2170-2180, 2008.

42. Ekman S, Frödin JE, Harmenberg J, Bergman A, Hedlund A, Dahg P, Alvfors C, Ståhl B, Bergström S and Bergqvist M Clinical phase I study with an insulin-like growth factor-1 receptor inhibitor: Experiences in patients with squamous non-small cell lung carcinoma. Acta Oncol 50: 441-447, 2011.

43. Wu X, Sooman L, Wickström M, Fryknäs M, Dyrager C, Lennartsson $\mathrm{J}$ and Gullbo J: Alternative cytotoxic effects of the postulated IGF-IR inhibitor picropodophyllin in vitro. Mol Cancer Ther 12: 1526-1536, 2013.

44. Rodrigues Alves APN, Fernandes JC, Fenerich BA, Coelho-Silva JL, Scheucher PS, Simões BP, Rego EM, Ridley AJ, Machado-Neto JA and Traina F: IGF1R/IRS1 targeting has cytotoxic activity and inhibits PI3K/AKT/mTOR and MAPK signaling in acute lymphoblastic leukemia cells. Cancer Lett 456 : 59-68, 2019.

This work is licensed under a Creative Commons Attribution-NonCommercial-NoDerivatives 4.0 International (CC BY-NC-ND 4.0) License. 